\title{
West Asia
}

\author{
International projects - including an advanced particle \\ accelerator and educational facilities - bolster this \\ region's focus on chemistry and physical sciences.
}

\author{
ARTICLE COUNT (AC): 1,927 \\ FRACTIONAL COUNT (FC): 853 \\ WEIGHTED FRACTIONAL COUNT (WFC): 753
}

$\mathrm{T}$ This is a region divided. Ongoing conflict has stopped some countries from sponsoring the development of science or maintaining safe facilities for researchers but not all. A number of nations, notably Israel and Turkey, have made inroads into supporting growth of their scientific communities or are adopting plans to do so.

Israel remains the region's leading scientific country and the only nation in the Index to break into the global top 20 based on weighted fractional count (WFC). Israel's WFC of 492 was significantly higher than both Turkey, second in the region with 79, and Saudi Arabia at 76. This success has been driven in part by high spending levels on R\&D, which in Israel is 3.9\% of GDP second only to South Korea, according to 2014 figures by United Nations Educational, Scientific and Cultural Organization (UNESCO).

Israel's R\&D spending is even driving hightech work. In 2014, for example, an international team - led by Israeli scientists - reported in Nature Nanotechnology on a new DNA-based structure that might be used in electronics. Although this work remains in its early stages, the authors concluded: "Our results pave a way towards the implementation of DNA-based programmable circuits for molecular electronics."

Israel's Weizmann Institute is the top institution in the region with a WFC of 143, slightly below its 2013 figure. It has a relatively evenly spread publication count across disciplines
— producing the highest outputs in life sciences and physical sciences, followed by chemistry. Globally this institute is 64th based on WFC, and it is 21st on the Index's list of institutions around the world for WFC in Nature and Science.

However, despite these impressive statistics, research at Weizmann - and indeed within the country as a whole - is lacking in one key area. "While Israel invests significantly in R\&D, particularly in information and communication technologies, the investments in biotech might be lagging behind," says Michal Neeman, vice

\section{"YOU CAN'T JUST IMPORT RESEARCH BY HIRING A FEW EXPATRIATES WHO ARE WORLD RENOWNED."}

president of the Weizmann Institute. The institute is working on filling in these gaps with its recently established Nancy and Stephen Grand Israel National Centre for Personalized Medicine. Created in 2013 with US $\$ 150$ million in donations, according to Neeman, the centre aims to lead Israel's research in genomics, protein profiling, bioinformatics and drug discovery. Its steering committee comprises leaders from several universities in Israel, which helps facilitate research collaborations across institutions.
Overall, Weizmann lags behind the region in collaboration. Whilst around half of its articles are the result of collaborative efforts, other institutions in the region are even more prolific in establishing research networks to drive publications.

\section{BIG SPENDERS STILL COLLABORATE}

Other countries in the region are also making significant R\&D investments. Turkey's investment has grown every year since 1995 , and is now just under $1 \%$ of GDP. Since 2000, Turkey also has developed national science, technology and innovation policies, including the establishment of the Turkish Research Area (TARAL) in 2004. This provides a forum for the country's stakeholders in research and innovation, including public agencies, universities, nongovernmental organizations and the private sector. Such investments and policies appear to be paying off: the number of researchers employed and papers published are both on the rise. In this Index, Turkey ranked 36, having overtaken Iran and Saudi Arabia.

To further extend Turkey's science capabilities, the government encourages international collaboration - to this end the Scientific and Technological Research Council of Turkey (TÜBİTAK) provides fellowships for foreign $\mathrm{PhD}$ students and postdoctoral scientists.

Strong research output requires more than big investments. Saudi Arabia has poured billions into new universities, particularly with

\section{WEST ASIA ANALYSIS}

Countries' weighted fractional count (WFC)

Region-leader Israel contributed $65 \%$ of the output, and Turkey,

Saudi Arabia and Iran added around 10\% each.

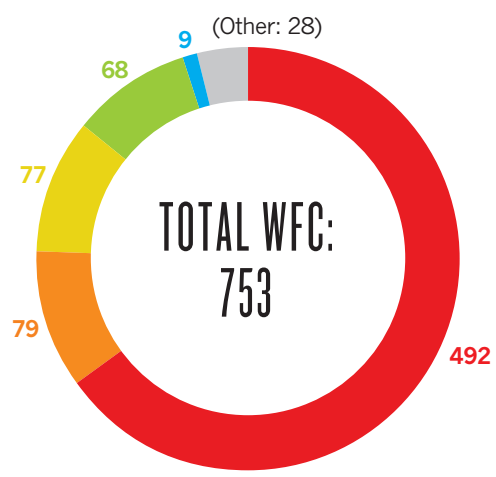

Relative subject area distribution

Four of the top five countries published at least $40 \%$ of their Index articles in the physical sciences.*

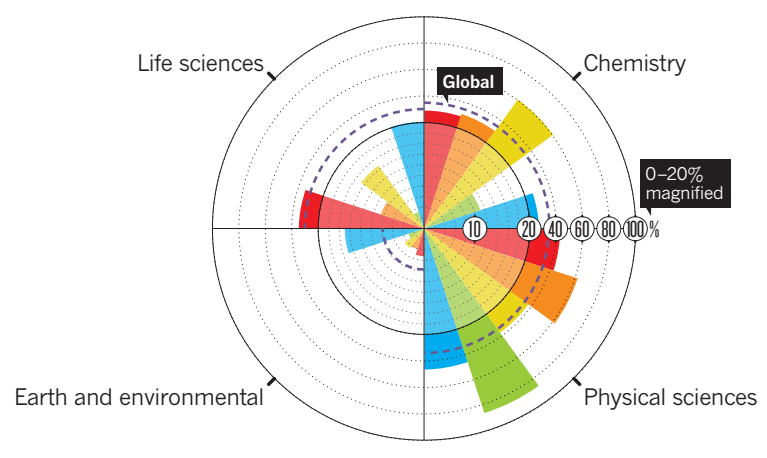

*Each slice represents the proportion each subject area contributes to a country's 
the 2009 opening of King Abdullah University of Science and Technology (KAUST), which is believed to have a US $\$ 15$ billion endowment, and has attracted top talent for research. From 2012 KAUST has increased its article output in the Nature Index by $40 \%$. Given its more moderate increase in WFC over the same time period, it seems that KAUST researchers are actively contributing more to collaborative papers than working in isolation.

Performance in the Nature Index is also greatly dependent on collaboration - and this is where the Arab states are doing well. Saudi Arabia reaches out extensively to other countries for scientific collaboration, with $79 \%$ of its output being the result of international collaborations. Israel and Turkey collaborated internationally on $46 \%$ and $59 \%$ of their papers, respectively, showing that scientists in Saudi Arabia collaborate much more than their colleagues in neighbouring countries. This high collaboration rate, however, may be due in part to the practice at some universities - although not KAUST, which opposes such an approach — of bringing in foreign researchers for a short amount of time to add a local affiliation to papers.

Even higher international collaboration rates apply to other wealthy Gulf countries that have invested in higher education, such as the United Arab Emirates (UAE) and Qatar. Both countries host campuses for foreign institutions, including New York University, Weill Cornell Medical College, Northwestern University and ParisSorbonne. The UAE's AC is 4.3 times its FC, while Qatar's is 5.8 times larger, supported by significant scientific collaborations.

Collaborations can help stimulate organic improvement of science by educating homegrown researchers. Leaders in the region understand the value of educating a scientific workforce. "Building [an] education system and stimulating research must be entrenched within society," says Khaled Toukan, the chairman of the Jordan Atomic Energy Commission and the country's former minister for Higher Education and Scientific Research. "You can't just import

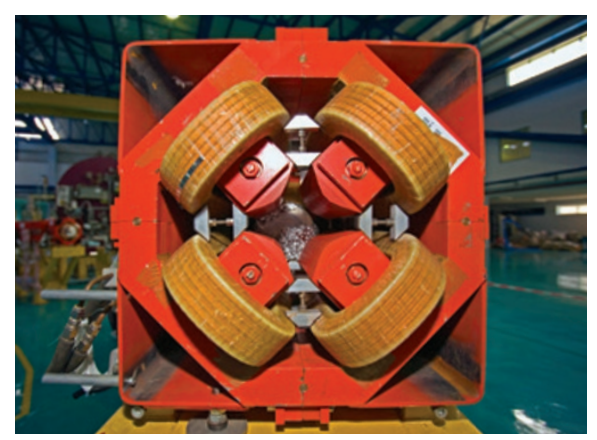

These brown magnets will focus the electron beam in the SESAME particle accelerator in Jordan.

it by hiring a few expatriates who are world renowned and they sit and publish papers."

Jordan lacks the bountiful energy resources enjoyed by other countries in the region including Saudi Arabia, the UAE and Qatar, which allow them to super-charge their research budgets. Instead, the country - which is yet to break into the top 100 - is having to slowly build its scientific community from the bottom up, a process that will probably require working with other countries. To build its first reactor for nuclear research, for example, Jordan's Board of Commissioners of the Energy and Mineral Resources Regulatory Commission sought the help of the Korea Institute of Nuclear Safety. Korean experts will help to build and run the facility, expected to be operational in 2016 at the Jordan University of Science and Technology in Irbid.

\section{ACCELERATING INTERNATIONAL SCIENCE}

Two big projects in Jordan should help improve national and international collaboration, Toukan says. Two 1,000-megawatt nuclear reactors are to be constructed in the northern part of the country through a US $\$ 10$ billion partnership with Russia, and the Synchrotron-light for Experimental Science and Applications in the Middle East (SESAME) in Allan, Jordan will be the first particle accelerator in the region.

SESAME's leaders hoped to get the facility online by the end of 2015. But a severe snowstorm in December 2013 caused the roof of the experimental hall at SESAME to cave in, which set the project back by a year. A new roof has been built and construction has resumed. The plan now is to have two beam lines ready by the end of 2016, one for hard X-rays - those with the highest energy - and one for infrared spectromicroscopy. With these lines, researchers hope to investigate, for example, cells and viruses and make breakthroughs in medicine.

The SESAME site certainly won't be among the largest particle accelerators in the world. Its storage ring is only 133 metres in circumference - compared to 1,500 metres for SPring 8 in Japan — but it will be able to accommodate several experiments at a time when all of its 25 beam lines are functioning.

SESAME is an ambitious project on many levels. Launched by UNESCO, with oversight from CERN, it is receiving input and support from some of the top scientific leaders in countries including Germany, France and Italy. But its primary aim is to serve researchers in the region who come from areas with deeply divided politics, including Egypt, Iran, Israel, Palestine, Turkey, Bahrain, Pakistan and Jordan.

"This is a positive [move], where rather than destroying each other, people are working together to promote science for peace, harmony and positive contribution to the modern world," says Toukan.

The hope is that SESAME can help alleviate persistent drawbacks for the region, including brain-drain, a lack of collaboration among researchers and low numbers of published papers. The laboratory could become a home for researchers considering going abroad or it might even lure back scientists who have already left. And with all the applications of synchrotrons, it could bring together researchers who would have otherwise never interacted.

"To survive in a global market, you really have to build industry," Toukan says. "And the only way to do it is through advanced scientific research and development, which the countries in this region realize now."

\section{WEST ASIA ANALYSIS}

Top 5 institutions' relative subject area distribution Israel's Weizmann Institute of Science led the region, and it published about equally in life and physical sciences.*

Weizmann Institute of Science

Hebrew University of Jerusalem

Tel Aviv University

Technion-Israel Institute of Technology

King Abdullah University of Science and Technology

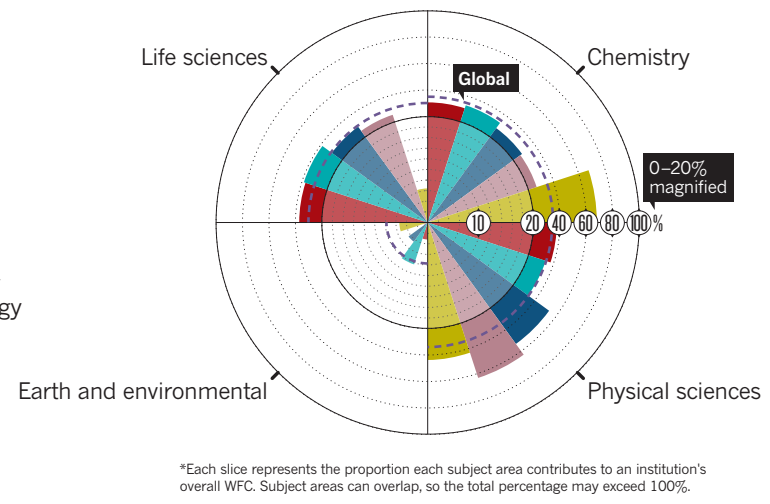

Top 5 institutions' collaborativeness Among the top five, the Weizmann Institute of Science published the most but collaborated the least.*

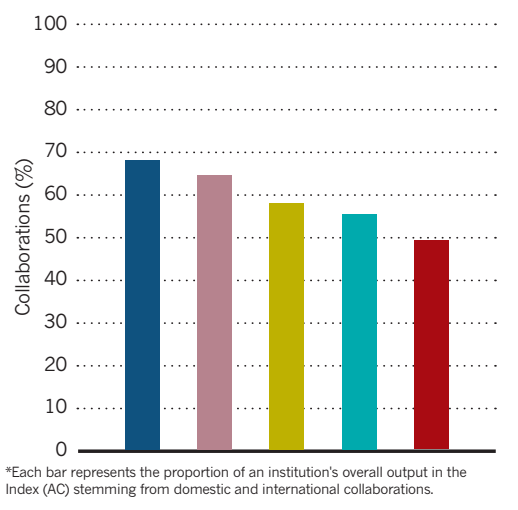

